\title{
A phase I trial of ganetespib in combination with paclitaxel and trastuzumab in patients with human epidermal growth factor receptor- 2 (HER2)-positive metastatic breast cancer
}

Komal Jhaveri ${ }^{1 \dagger}$, Rui Wang ${ }^{1 \dagger}$, Eleonora Teplinsky ${ }^{2}$, Sarat Chandarlapaty ${ }^{1}$, David Solit ${ }^{1}$, Karen Cadoo ${ }^{1}$, James Speyer ${ }^{3}$, Gabriella D'Andrea', Sylvia Adams³, Sujata Patil', Sofia Haque', Tara O'Neill', Kent Friedman², Francisco J. Esteva ${ }^{3}$, Clifford Hudis ${ }^{1}$ and Shanu Modi ${ }^{1 *}$

\begin{abstract}
Background: Targeted therapies in HER2-positive metastatic breast cancer significantly improve outcomes but efficacy is limited by therapeutic resistance. HER2 is an acutely sensitive Heat Shock Protein 90 (HSP90) client and HSP90 inhibition can overcome trastuzumab resistance. Preclinical data suggest that HSP90 inhibition is synergistic with taxanes with the potential for significant clinical activity. We therefore tested ganetespib, a HSP90 inhibitor, in combination with paclitaxel and trastuzumab in patients with trastuzumab-refractory HER2-positive metastatic breast cancer.
\end{abstract}

Methods: In this phase I dose-escalation study, patients with trastuzumab-resistant HER2-positive metastatic breast cancer received weekly trastuzumab (2 mg/ $/ \mathrm{kg})$ and paclitaxel $\left(80 \mathrm{mg} / \mathrm{m}^{2}\right)$ on days $1,8,15$, and 22 of a 28-day cycle with escalating doses of ganetespib $\left(100 \mathrm{mg} / \mathrm{m}^{2}, 150 \mathrm{mg} / \mathrm{m}^{2}\right.$, and a third cohort of $125 \mathrm{mg} / \mathrm{m}^{2}$ if needed) on days 1,8 , and 15 . Therapy was continued until disease progression or toxicity. The primary objective was to establish the safety and maximum tolerated dose and/or recommended phase II dose (RP2D) of this therapy. The secondary objectives included evaluation of the effects of ganetespib on the pharmacokinetics of paclitaxel, and to make a preliminary assessment of the efficacy of the combination therapy.

Results: Dose escalation was completed for the two main cohorts without any observed dose-limiting toxicities. Nine patients received treatment. The median prior lines of anti-HER2 therapy numbered three (range 2-4), including prior pertuzumab in 9/9 patients and ado-trastuzumab emtansine (T-DM1) in 8/9 patients. The most common grade $1 / 2$ adverse events (AEs) were diarrhea, fatigue, anemia, and rash. There were no grade 4 AEs related to ganetespib. The overall response rate was 22\% (2/9 patients had partial response) and stable disease was seen in 56\% (5/9 patients). The clinical benefit rate was 44\% (4/9 patients). The median progression-free survival was 20 weeks (range $8-55$ ).

(Continued on next page)

\footnotetext{
* Correspondence: modis@mskcc.org

${ }^{\dagger}$ Equal contributors

${ }^{1}$ Memorial Sloan-Kettering Cancer Center, New York, NY, USA

Full list of author information is available at the end of the article
} 
(Continued from previous page)

Conclusion: The RP2D of ganetespib is $150 \mathrm{mg} / \mathrm{m}^{2}$ in combination with weekly paclitaxel plus trastuzumab. The combination was safe and well tolerated. Despite prior taxanes, pertuzumab, and T-DM1, clinical activity of this triplet regimen in this heavily pretreated cohort is promising and warrants further study in HER2-positive metastatic breast cancer.

Trial registration: ClinicalTrials.gov NCT02060253. Registered 30 January 2014.

Keywords: Ganetespib, Paclitaxel, Trastuzumab, HSP90 inhibitor, HER2, Metastatic breast cancer, Phase I trial

\section{Background}

HER2-positive disease accounts for $15-20 \%$ of breast cancers, and traditionally has an aggressive clinical course and inferior survival outcome [1-3]. Clinical benefits from trastuzumab and other anti-HER2 therapies have greatly improved results for patients with HER2-positive disease, but are limited by the development of resistance [4].

HSP90 belongs to a class of molecular chaperone proteins that help modulate cellular responses to environmental stress [5]. In particular, HSP90 regulates the folding, stability, and function of many cellular proteins including several receptor tyrosine kinases (RTKS). Inhibition of HSP90 is believed to cause these client proteins to adopt conformations which stimulate their ubiquitination and degradation by the proteasome [6-10]. HER2 is one of the most sensitive HSP90 clients, and HER2-amplified breast cancer cells are potently inhibited by geldanamycin, the prototype HSP90 inhibitor [11, 12]. Multiple first-generation geldanamycin-derived HSP90 inhibitors have been evaluated for the treatment of HER2-positive breast cancer [13-16]. The greatest clinical activity was reported with tanespimycin (17-AAG) in combination with trastuzumab in trastuzumab-refractory HER2positive metastatic breast cancer with a response rate of $22 \%$ and a clinical benefit rate (CBR) of $59 \%[15,16]$. Another phase I trial of alvespimycin plus trastuzumab reported one partial response (PR) and six cases of stable disease (SD) lasting $>6$ months in patients with HER2positive metastatic breast cancer [14]. A phase II study of retaspimycin (IPI-504) in combination with trastuzumab was also found to be well tolerated with modest antitumor effects (62\% of patients had stable disease) [13]. Ganetespib ((5-(2,4-dihydroxy-5-(1-methylethyl)phenyl)4-(1-methyl-1H-indol-5-yl)-2,4-dihydro-(1,2,4)triazol-3one)) is a second-generation synthetic small molecule that binds to the ATP pocket in the N-terminus of HSP90 [17-19], is structurally unrelated to geldanamycin-derived inhibitors, and has demonstrated significant activity for downregulating HSP90 client protein levels preclinically. Specifically, ganetespib showed stronger anti-tumor activity compared to tanespimycin over a broader range of breast cancer subtypes, including HER2-normal cancer and triplenegative breast cancer (TNBC), with a more favorable safety profile, including lack of hepatotoxicity and ocular toxicity $[18,19]$. We recently reported a single-arm phase II study of single-agent ganetespib in unselected patients with heavily treated metastatic breast cancer who received up to three lines of chemotherapy [19]. That study did not meet the prespecified criteria for overall response in the first stage in a heavily pretreated group of patients; however, there were two confirmed PRs and six cases of SD in patients with HER2-positive, trastuzumab-refractory metastatic breast cancer that further justified its study for this subtype of breast cancer [19].

A novel approach to the treatment of metastatic breast cancer is the combination of HSP90 inhibitors and taxanes. Taxanes disrupt an essential structural component (microtubules) of mitosis, and HSP90 inhibitors impact the regulatory (checkpoint) proteins controlling progression through the cell cycle [20]. In addition, both drugs disrupt other critical facets of cell growth and proliferation, adding to their potential combined efficacy [20-22]. When paclitaxel was given with HSP90 inhibitors in nude mice bearing tumor xenografts, there was a 5-fold-22-fold enhancement of cytotoxicity [20]. Maximal synergistic anti-tumor activity was seen in breast cancer xenografts when tanespimycin and paclitaxel were administered sequentially on the same day [21]. Importantly, the addition of tanespimycin to cells after exposure to paclitaxel significantly increased both the activation of caspases 9 and 3 and thus apoptosis, indicating that the sequence of drugs (paclitaxel followed by HSP90 inhibitor) matters and influences efficacy [22].

The primary objective of this study was to establish the safety, tolerability, maximum tolerated dose (MTD), and/or recommended phase II dose (RP2D) of ganetespib plus paclitaxel in conjunction with trastuzumab in patients with HER2-positive metastatic breast cancer. The secondary objectives included evaluation of the possible effects of ganetespib on the pharmacokinetics (PK) of paclitaxel, and to make a preliminary assessment of the efficacy of the combination.

\section{Methods}

\section{Study design and patient selection}

Patients were eligible if they were aged $\geq 18$ years, had locally advanced or metastatic HER2-positive disease 
(defined as FISH ratio $\geq 2.0$ or immunohistochemistry (IHC) $3+$ ), ECOG $\leq 2$, measurable disease per RECIST 1.1 [23], and adequate end organ function (defined as hemoglobin $\geq 9 \mathrm{~g} / \mathrm{dl}$, absolute neutrophil count $(\mathrm{ANC}) \geq$ $1.5 \times 10^{9} / \mathrm{L}$, platelets $\geq 100 \times 10^{9} / \mathrm{L}$, bilirubin $\leq 1.5$ upper limit of normal (ULN), aspartate aminotransferase (AST) and alanine aminotransferase (ALT) $\leq 2.5$ ULN, and serum creatinine $\leq 1.5 \mathrm{ULN}$ ). Patients must have received prior trastuzumab and those with estrogen receptor (ER)-positive disease must have received prior endocrine therapy. Any number of prior lines of chemotherapy in the metastatic setting was allowed. Progression on prior treatment with pertuzumab and T-DM1 was required (unless heavily pretreated prior to FDA approval of pertuzumab for first-line treatment of HER2-positive metastatic breast cancer (6/2012) and/or T-DM1 (2/2013)).

Patients were excluded if they were pregnant or lactating, had prior grade 3 hypersensitivity to cremophor or trastuzumab, had prior HSP90 inhibitor therapy, had active central nervous system metastases, New York Heart Association (NYHA) class III/IV congestive heart failure requiring active treatment, left ventricular ejection fraction (LVEF) $<50 \%$ at baseline, baseline QTc $>470$ milliseconds, or grade $\geq 2$ peripheral neuropathy, were on any medications known to prolong QTc, had preexisting left bundle branch block (LBBB), history of uncontrolled dysrhythmias, or a requirement for antiarrhythmics, had myocardial infarction (MI) or ischemic heart disease within 6 months, or had known active infection with HIV or hepatitis B or $C$ viruses.

The study was approved by the institutional research ethics board of Memorial Sloan Kettering Cancer Center and New York University Langone Medical Center. All participants gave informed consent before they entered the study.

\section{Study treatment}

Patients received intravenous infusions of trastuzumab and paclitaxel with ganetespib on days 1,8 , and 15 and of trastuzumab and paclitaxel on day 22 of a 28-day cycle. The sequence of administration was trastuzumab $(2 \mathrm{mg} / \mathrm{kg})$ followed by paclitaxel $\left(80 \mathrm{mg} / \mathrm{m}^{2}\right)$ followed by ganetespib. If the patient's last dose of trastuzumab was $>21$ days before enrollment, they received a loading dose of trastuzumab at $4 \mathrm{mg} / \mathrm{kg}$ over 90 minutes. Ganetespib was then administered intravenously over 60 minutes. The starting dose of ganetespib was $100 \mathrm{mg} / \mathrm{m}^{2}$, and if there were no DLTs the next cohort would escalate to $150 \mathrm{mg} / \mathrm{m}^{2}$. A further dose level of $125 \mathrm{mg} / \mathrm{m}^{2}$ was incorporated in the circumstance of good tolerance of the $100 \mathrm{mg} / \mathrm{m}^{2}$ but poor tolerance of the $150 \mathrm{mg} / \mathrm{m}^{2}$ dose levels. There was no dose escalation for paclitaxel and trastuzumab. Therapy was continued until disease progression or unacceptable toxicity.

\section{Toxicity assessment and dose reductions}

Patients were examined and assessed for toxicities during and prior to each cycle. Toxicity was graded according to National Cancer Institute (NCI) CTCAE version 4.0 (http://ctep.cancer.gov/protocolDevelopment/electronic _applications/ctc.htm\#ctc_40). Patients were evaluated for DLT during cycle 1. DLT was defined as any drugrelated grade $\geq 4$ nonhematologic adverse events (AEs) or any grade 3 nonhematologic AEs not improving to baseline or grade $\leq 1$ by day 14 ; grade 4 neutropenia lasting $\geq$ 7 days, or febrile neutropenia, grade 4 thrombocytopenia, or any grade 3 thrombocytopenia that has not recovered to grade $\leq 2$ by day 7 ; or any treatment-related toxicity prompting a dose reduction of ganetespib during the DLT observation period.

Paclitaxel dose reductions were not permitted during the DLT observation period. For dosing beyond cycle 1, paclitaxel was held if patients experienced any other grade 3 or 4 toxicity thought to be related to paclitaxel until symptoms resolved to grade $1 /$ baseline grade. One dose reduction for paclitaxel to $65 \mathrm{mg} / \mathrm{m}^{2}$ was permitted.

\section{Assessment of treatment response}

Patients were evaluated for response initially after two cycles and then every three cycles thereafter using the RECIST criteria [23]. All patients with PR or complete response $(\mathrm{CR})$ were required to have confirmation of response 4 weeks after the criteria for response were first met. The best overall response was defined as the best response recorded from the start of treatment until disease progression or withdrawal from the study. All patients who received at least one full cycle (4 weeks) of ganetespib, paclitaxel, and trastuzumab and had a follow-up assessment were evaluable for response. The CBR was defined as the proportion of patients whose best overall response, according to RECIST, was CR, PR, or SD lasting for at least 24 weeks.

\section{Pharmacokinetics of paclitaxel assessment}

Blood samples for determination of plasma concentrations of paclitaxel were collected on cycle 1 , day 8 through cycle 1, day 9 at the following time points after trastuzumab infusion and relative to the start of the paclitaxel infusion: 5 minutes prior to treatment, and 30 and 60 minutes (immediately prior to stopping the paclitaxel infusion pump and starting the ganetespib infusion) after start of paclitaxel infusion. Blood samples were also collected at the following time points after starting ganetespib infusion: 1.5, 2, 4, 7, 21, 24, 27, and 31 hours. Each blood sample $(3-5 \mathrm{ml})$ was collected in sodium heparin tubes and transferred into two polypropylene 
Table 1 Patient demographics

\begin{tabular}{|c|c|}
\hline Baseline characteristic & Number \\
\hline Total enrolled & 9 \\
\hline Median (range) age (years) at study enrollment & $46(29-65)$ \\
\hline \multicolumn{2}{|l|}{ Subtype } \\
\hline $\mathrm{ER}+/ \mathrm{HER} 2+$ & 7 \\
\hline ER-/HER2+ & 2 \\
\hline Median ECOG performance status & $0(0-1)$ \\
\hline $\begin{array}{l}\text { Prior lines of chemotherapy in the metastatic } \\
\text { setting, median (range) }\end{array}$ & $3(2-6)$ \\
\hline $\begin{array}{l}\text { Prior lines of endocrine therapies in the } \\
\text { metastatic setting, median (range) }\end{array}$ & $1(1-3)$ \\
\hline $\begin{array}{l}\text { Prior number of anti-HER2 agents in the } \\
\text { metastatic setting, median (range) }\end{array}$ & $3(2-4)$ \\
\hline
\end{tabular}

tubes $\left(1 \mathrm{ml}\right.$ each) and stored at $-80{ }^{\circ} \mathrm{C}$. PK were performed in collaboration with Synta Pharmaceuticals, Inc. PK parameters of paclitaxel (such as the area under the curve (AUC) and the maximum serum concentration (Cmax)) were examined descriptively to evaluate the effect of ganetespib on these measures.

\section{Results}

\section{Patients and treatment}

Nine patients were enrolled into two dose cohorts: three patients at $100 \mathrm{mg} / \mathrm{m}^{2}$ and six patients at $150 \mathrm{mg} / \mathrm{m}^{2}$. Patient demographics are presented in Table 1 . The median age was 46 (range 29-65) years and median ECOG performance status was 0 (range $0-1$, Table 1). Seven out of nine patients had ER-positive/HER2-positive breast cancer, and two patients had ER-negative/HER2positive breast cancer. Patients were heavily pretreated with a median of three (range 2-6) lines of chemotherapy and three prior (range 2-4) anti-HER2 therapies in the metastatic setting, including prior pertuzumab in $9 / 9$ patients and T-DM1 in 8/9 patients. For patients with ERpositive breast cancer, the median number of prior lines of endocrine therapy in the metastatic setting was one (range $1-3$, Table 1).

\section{Overall safety}

All nine patients were included in the safety analysis. No patients voluntarily withdrew from the study and no patients were taken off study due to toxicities. There were no grade 4 AEs related to ganetespib. The most common drug-related AEs were diarrhea (grade 1/2, 78\%), fatigue (grade $1 / 2,67 \%$ ), anemia (grade $1 / 2,44 \%$ ), rash (grade $1 / 2,32 \%$ ), elevated AST or ALT (grade $1 / 2,32 \%$ ), and nausea (grade $1 / 2,32 \%$ ) (Fig. 1). The diarrhea was well managed with pre/supportive medications (Fig. 1). Ganetespib-related grade 3 AEs were minimal, and included pruritus (one patient), decreased phosphorus (one patient), and increased ALT (one patient), all of which resolved with dose delays of up to 1 week (Table 2). One patient had grade 3 blurred vision and dry eyes which was attributable to paclitaxel; she had experienced these symptoms with prior paclitaxel therapy and they resolved with the discontinuation of paclitaxel. There were no further episodes of blurry vision when the paclitaxel dose was reduced to $65 \mathrm{mg} / \mathrm{m}^{2}$ in this patient. No patients on study required ganetespib dose reductions. There were no deaths on study.

\section{Anti-tumor activity}

Of the nine patients enrolled, confirmed partial tumor responses were achieved in two of the nine patients, both in the $150 \mathrm{mg} / \mathrm{m}^{2}$ cohort for an overall response rate (ORR) of $22 \%$. Five additional patients achieved SD (56\%), and duration of SD ranged from 11 to 29 weeks. The CBR was $44 \%$ (4/9 patients). Representative CT

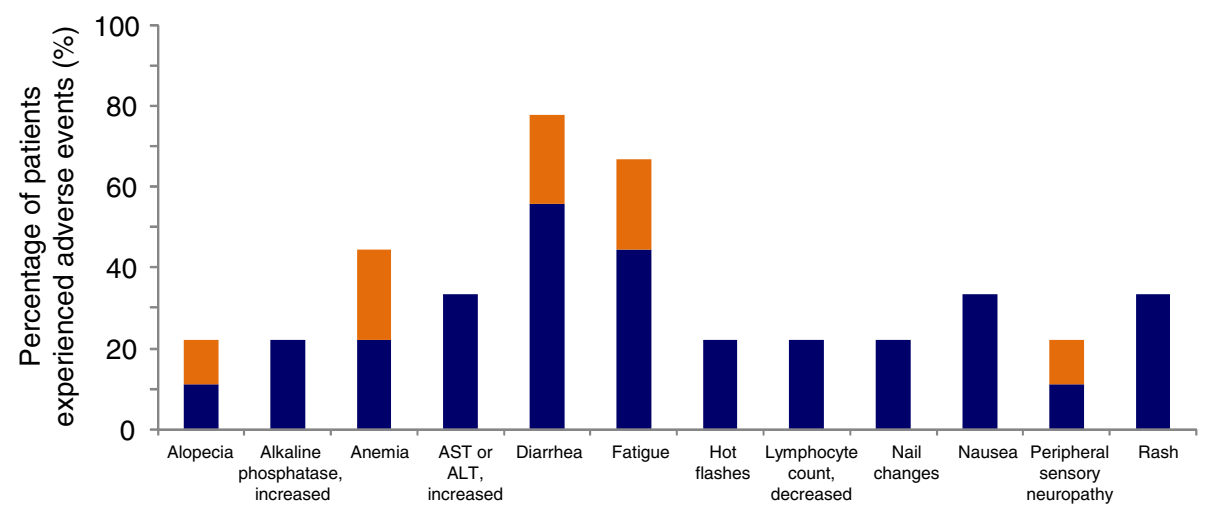

Fig. 1 Most common ganetespib-related grade 1/2 AEs in $\geq 20 \%$ of patients. None of the nine patients experienced DLTs. ALT alanine aminotransferase, AST aspartate transaminase 
Table 2 Ganetespib-related grade 3 adverse events

\begin{tabular}{lll}
\hline$N \quad \begin{array}{l}\text { Ganetespib-related grade } 3 \\
\text { adverse events }\end{array}$ & Outcome \\
\hline $1^{\text {a }}$ & $\begin{array}{l}\text { Grade } 3 \text { blurred vision/grade } \\
3 \text { dry eyes (in same patient) }\end{array}$ & $\begin{array}{l}\text { Blurred vision: dose held for } 1 \text { week } \\
\text { until } \leq \text { grade } 1 \text { and paclitaxel dose } \\
\text { reduced to } 65 \mathrm{mg} / \mathrm{m}^{2} / \text { Dry eyes: no } \\
\text { action taken: resolved in } 1 \text { week }\end{array}$ \\
1 & $\begin{array}{l}\text { While attributed to ganetespib, } \\
\text { symptoms resolved after paclitaxel } \\
\text { was held }\end{array}$ \\
1 Grade 3 phosphorus, & No action taken; resolved in 1 day \\
decreased & Grade 3 ALT, increased & $\begin{array}{l}\text { Ganetespib and paclitaxel dose held } \\
\text { for } 1 \text { week; resolved in } 1 \text { week }\end{array}$
\end{tabular}

ALT alanine aminotransferase

${ }^{a}$ One patient had blurred vision and dry eyes which were felt to be attributable to paclitaxel based on her having similar symptoms when treated with paclitaxel in the past. She was followed by an ophthalmologist for this toxicity which resolved with the discontinuation of paclitaxel

scans prior to and after this triplet regimen in a patient with chest wall soft tissue metastasis who achieved PR are shown in Fig. 2.

\section{Pharmacokinetics}

PK evaluations were carried out in all nine patients to evaluate the effect of ganetespib on the paclitaxel absorption. Table 3 presents the PK parameters for ganetespib at cycle 1 , day 8 through cycle 1 , day 9 . Trastuzumab was administered before the PK samples were taken. Paclitaxel PK data are not appreciably different from those reported in the literature taking into account differences in dose and sampling scheme (Table 3, Fig. 3) $[24,25]$. There was no effect of ganetespib on paclitaxel $\mathrm{PK}$ at the dose of $150 \mathrm{mg} / \mathrm{m}^{2}$. For paclitaxel, the AUC was $6280 \mathrm{~h} * \mathrm{ng} / \mathrm{ml}$, the elimination half-life $\left(\mathrm{T}_{1 /}\right.$ 2) was 13.6 hours, the Cmax was $3750 \mathrm{ng} / \mathrm{ml}$, the clearance was $13.4 \mathrm{~L} / \mathrm{h} / \mathrm{m}^{2}$, and the mean resident time (MRT) was 9.0 hours (Table 3 ).

\section{Discussion}

HSP90 is a molecular chaperone, supporting a number of cellular onco-proteins that are critical for cancer cell survival and progression. Inhibition of HSP90 therefore has the potential to simultaneously disrupt multiple signaling pathways in cancer cells and hence has been an extensively investigated and highly sought-after strategy for cancer therapy [5-10, 26]. Previous studies have shown clinical anti-tumor activity with various different HSP90 inhibitors [13-19]. Preclinical studies have shown synergistic anti-tumor effects with no additional adverse effects when HSP90 inhibitors have been combined with taxanes [18-20]. The randomized phase II GALAXY-I trial of ganetespib and docetaxel demonstrated improved overall survival in the combination arm compared with docetaxel alone, for the second-line setting in patients with advanced NSCLC who were at least 6 months from initial diagnosis of advanced disease [27].

This phase Ib trial is the first to report on the use of ganetespib in combination with paclitaxel and trastuzumab for patients with HER2-positive metastatic breast cancer. Consistent with the preclinical experience, the combination of paclitaxel and trastuzumab with ganetespib was well tolerated. The AEs observed were largely grade 1 or 2 in nature and included diarrhea, fatigue, anemia, rash, and nausea. This study and our previously reported phase II study with single-agent ganetespib [19] together did not reveal significant off-target DLTs such as hepatotoxicity and cardiotoxicity (congestive heart failure, QTc changes). Furthermore, compared to other HSP90 inhibitors, we observed a low rate of ocular toxicity/retinal injury in this trial. There was one patient who experienced grade 3 dry eye and blurry vision, but her symptoms were related to paclitaxel and resolved with its discontinuation.

The combination of paclitaxel, trastuzumab, and ganetespib was clinically active, with two PRs (22\%) in patients with heavily pretreated trastuzumab-refractory HER2-
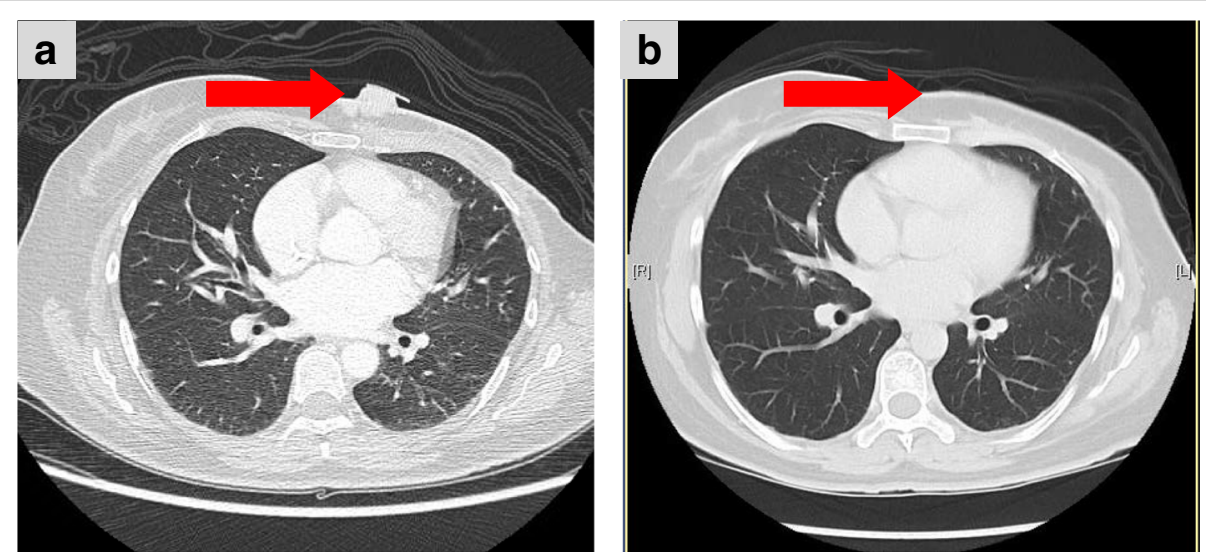

Fig. 2 Baseline and follow-up CT scans. Baseline (a) and follow-up (b) CT scans of a 43-year-old patient with left chest wall soft tissue metastases 
Table 3 Paclitaxel pharmacokinetics

\begin{tabular}{|c|c|c|c|c|c|c|c|}
\hline $\begin{array}{l}\text { Ganetespib } \\
\left(\mathrm{mg} / \mathrm{m}^{2}\right)\end{array}$ & Number & $\begin{array}{l}\text { Cmax } \\
(\mathrm{ng} / \mathrm{ml})\end{array}$ & $\begin{array}{l}\text { Tmax } \\
\text { (hours) }\end{array}$ & $\begin{array}{l}\mathrm{T}_{1 / 2} \\
\text { (hours) }\end{array}$ & $\begin{array}{l}\text { AUC } \\
\left(h^{*} n g / m l\right)\end{array}$ & $\begin{array}{l}\mathrm{CL} \\
\left(\mathrm{L} / \mathrm{h} / \mathrm{m}^{2}\right)\end{array}$ & $\begin{array}{l}\text { MRT } \\
\text { (hours) }\end{array}$ \\
\hline 100 & 3 & $3340 \pm 1270$ & $0.8 \pm 0.3$ & $12.9 \pm 0.4$ & $5900 \pm 1440$ & $14.2 \pm 3.5$ & $8.5 \pm 0.8$ \\
\hline 150 & 6 & $3750 \pm 1370$ & $1.0 \pm 0.0$ & $13.6 \pm 3.3$ & $6280 \pm 1430$ & $13.4 \pm 3.2$ & $9.0 \pm 4.0$ \\
\hline
\end{tabular}

Cmax maximum serum concentration, Tmax time of maximum serum concentration observed, $T_{1 / 2}$ half-life $A U C$ area under the curve, $C L$ clearance, $M R T$ mean resident time

positive metastatic breast cancer. Additionally, five patients achieved SD (56\%) with a CBR of 44\% (4/9 patients). Notably, in our previous phase II single-agent ganetespib trial, the ORR rate of ganetespib was $15 \%$ with two PRs in trastuzumab-refractory ER+/HER2+ metastatic breast cancer. There were seven SDs of which six were seen in patients with HER2-positive metastatic breast cancer and one in a patient with TNBC.

Aside from ganetespib, there are a number of other second-generation HSP90 inhibitors that are in preclinical or clinical testing, including resorcinol derivatives (NVP-AUY922, AT-13387, KW-2478), purine derivatives (CNF2024/BIIB021, PU-H71, MPC-3100, CUDC-305), and other inhibitors including SNX-5422, NVP-HSP990, and XL888 [28-42]. Some of these agents have been tested in patients with breast cancer. For example, a phase II expansion trial of single-agent NVP-AUY922 given intravenously to patients with HER2-positive and ERpositive breast cancer reported two partial metabolic responses on FDG-PET and one confirmed PR by RECIST among the 10 patients enrolled [29]. PU-H71, a purine derivative that is thought to be active in TNBC, has been studied in a phase I trial of patients with advanced solid tumors and lymphoma. The trial was completed recently and revealed a favorable safety profile and evidence of anti-

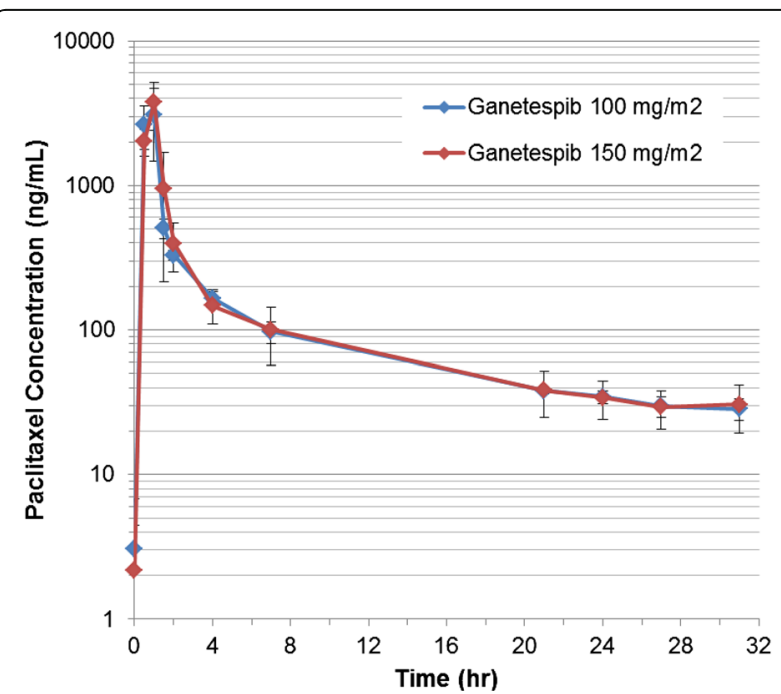

Fig. 3 Paclitaxel PK. Preliminary paclitaxel PK data for the nine study patients are not appreciably different from those reported in the literature tumor activity across a broad range of tumor types [43]. A phase Ib study of the combination of PU-H71 and nabpaclitaxel is planned for patients with HER2-negative metastatic breast cancer, including patients with triple-negative disease at Memorial Sloan Kettering Cancer Center.

Another heavily studied area in the field of HSP90 inhibitors is the identification of biomarkers and companion diagnostic assays which are crucial to identify patients most likely to respond to therapy. Our group conducted a retrospective study to explore potential biomarkers in patients treated with HSP90 inhibitors. Among many potential candidates analyzed (HER2, HSP90, HSP70, phosphotension homolog), HER2 was found to be the most important individual biomarker and the only one with correlation to response with HSP90 inhibitor therapy [44]. While tumor biopsies have been undertaken in some trials and can serve as a useful tool to establish target modulation, they provide only static information for a small part of the tumor and cannot account for the heterogeneity of metastatic tumor burden. In contrast, molecular imaging biomarkers allow for serial noninvasive assessments including providing data regarding spatial and temporal tumor uptake and retention. Additionally, they have the potential to serve as a predictive biomarker of response. In fact, direct molecular imaging using the labeled drug itself can guide patient selection, help measure tumor PK, and optimize the dose and schedule for this class of agents. For instance, a unique feature of PU-H71 is that it has an endogenous iodine atom $\left({ }^{127} \mathrm{I}\right)$, which was replaced with the PET radionuclide ${ }^{124} \mathrm{I}$ to result in the imaging agent, ${ }^{124}$ I-PU-H71 [45]. Importantly, the PET agent is molecularly identical to PU-H71 and its half-life of 4.02 days makes serial imaging practical. A phase 0 , first-inhuman trial of ${ }^{124} \mathrm{I}-\mathrm{PU}-\mathrm{H} 71$ in patients with advanced solid tumors and lymphoma not only determined the microdose biodistribution of PU-H71 but also ensured tracer avidity of tumors [45]. Tracer uptake at the metastatic tumor sites in this study correlated well with baseline CT and/or FDG-PET scans. The phase I clinical trial of PU-H71 in patients with advanced solid tumors and lymphoma also incorporated ${ }^{124} \mathrm{I}-\mathrm{PU}-\mathrm{H} 71$ PET to determine tumor PK and the intratumoral drug concentration. Findings from this study showed close concordance between intratumoral drug concentrations as determined by tumor biopsies with estimated measurements from ${ }^{124} \mathrm{I}$ - 
PU-H71 PET [46], highlighting the potential role of ${ }^{124} \mathrm{I}-$ PU-H71 PET as a biomarker to visualize PU-H71 uptake and to estimate intratumoral concentrations of the inhibitor.

\section{Conclusion}

The combination of ganetespib with paclitaxel plus trastuzumab is well tolerated, safe, and active with a RP2D of ganetespib at $150 \mathrm{mg} / \mathrm{m}^{2}$ in this triplet therapy. Based on the clinical activity in this heavily pretreated population, this combination warrants further study in HER2positive metastatic breast cancer. In addition, further exploration of biomarkers that predict sensitivity to ganetespib is a critical step for the optimal clinical development of this and other HSP90 inhibitors.

\begin{abstract}
Abbreviations
AE: Adverse event; ALT: Alanine aminotransferase; ANC: Absolute neutrophil count; AST: Aspartate aminotransferase; AUC: Area under the curve; CBR: Clinical benefit rate; Cmax: Maximum serum concentration; CR: complete response; CTCAE: Common terminology criteria for adverse events; DLT: Dose-limiting toxicity; ECOG: Eastern Cooperative Group; ER: Estrogen receptor; FDA: Food and Drug Administration; FDGPET: Fluorodeoxyglucose-positron emission tomography; FISH: Fluorescence in-situ hybridization; HER2: Human epidermal growth factor receptor 2; HSP90: Heat Shock Protein 90; IHC: Immunohistochemistry; LBBB: Left bundle branch block; LVEF: Left ventricular ejection fraction; MRT: Mean resident time; MTD: Maximum tolerated dose; NCl: National Cancer Institute; NSCLC: Nonsmall cell lung cancer; NYHA: New York Heart Association; ORR: Overall response rate; PK: Pharmacokinetic; PR: Partial response; RECIST: Response evaluation criteria in solid tumors; RP2D: Recommended phase II dose; RTK: Receptor tyrosine kinase; SD: Stable disease; $T_{1 / 2}$ : Half-life; T-DM1: Ado-trastuzumab emtansine; TNBC: Triple-negative breast cancer; ULN: Upper limit of normal
\end{abstract}

\section{Acknowledgements}

The authors thank the patients, their families, the nurses, and the investigators who participated in this study.

\section{Funding}

This study is an investigator-sponsored trial. The study was funded by Synta Pharmaceuticals. KJ received Terri Brodeur Breast Cancer Foundation support.

\section{Availability of data and materials}

Not applicable.

\section{Authors' contributions}

$\mathrm{KJ}$ and SM were involved in the design of the study, acquisition, analysis and interpretation of data, and drafting the manuscript. RW was involved in the analysis and interpretation of data, and drafting the manuscript. KJ, ET, SC, JS, GD, SA, KF, FJE, and SM enrolled patients. ET was also involved in data acquisition and analysis. SP participated in the statistical analysis and interpretation of data. TO participated in the data collection and organization. SH performed the interpretation of the radiological images. KC and DS helped with the manuscript editing. $\mathrm{CH}$ was involved with study design and manuscript editing. All authors read and approved the final manuscript.

\section{Ethics approval and consent to participate}

This clinical trial was conducted in accordance with Good Clinical Practice guidelines. Approval for the protocol was obtained from the institutional review board for both Memorial Sloan Kettering Cancer Center and New York University Langone Medical Center. All participants gave informed consent before they entered the study.

\section{Consent for publication}

All authors agreed to this publication.

\section{Competing interests}

The authors declare that they have no competing interests.

\section{Publisher's Note}

Springer Nature remains neutral with regard to jurisdictional claims in published maps and institutional affiliations.

\section{Author details}

${ }^{1}$ Memorial Sloan-Kettering Cancer Center, New York, NY, USA. ${ }^{2}$ Valley-Mount Sinai Comprehensive Cancer Care, Paramus, NJ, USA. ${ }^{3}$ Laura and Isaac Perlmutter Cancer Center at NYU Langone Medical Center, New York, NY, USA.

Received: 18 January 2017 Accepted: 7 July 2017

Published online: 02 August 2017

\section{References}

1. Wolff AC, Hammond ME, Hicks DG, Dowsett M, MCShane LM, Allison KH, et al. Recommendations for human epidermal growth factor receptor 2 testing in breast cancer: American Society of Clinical Oncology/College of American Pathologists clinical practice guideline update. J Clin Oncol. 2013;31:3997.

2. Bilous M, Morey AL, Armes JE, Bell R, Button PH, Cummings MC, et al. Assessing HER2 amplification in breast cancer: findings from the Australian In Situ Hybridization Program. Breast Cancer Res Treat. 2012;134:617.

3. Varga Z, Noske A, Ramach C, Padberg B, Moch H. Assessment of HER2 status in breast cancer: overall positivity rate and accuracy by fluorescence in situ hybridization and immunohistochemistry in a single institution over 12 years: a quality control study. BMC Cancer. 2013;13:615.

4. Nahta R, Yu D, Hung MC, Hortobagyi GN, Esteva FJ. Mechanisms of disease: understanding resistance to HER2-targeted therapy in human breast cancer. Nat Clin Pract Oncol. 2006;3:269.

5. Whitesell L. Lindquist SL.HSP90 and the chaperoning of cancer. Nat Rev Cancer. 2005;5:761.

6. Xu W, Neckers L. Targeting the molecular chaperone heat shock protein 90 provides a multifaceted effect on diverse cell signaling pathways of cancer cells. Clin Cancer Res. 2007;13:1625.

7. Weinstein IB. Cancer. Addiction to oncogenes-the Achilles heal of cancer. Science. 2002;297:63.

8. Jhaveri K, Modi S. HSP90 inhibitors for cancer therapy and overcoming drug resistance. Adv Pharmacol. 2012;65:471.

9. Jhaveri $\mathrm{K}$, Taldone T, Modi S, Chiosis G. Advances in the clinical development of heat shock protein 90 (HSP90) inhibitors in cancers. Biochim Biophys Acta. 2012;1823:742.

10. Jhaveri K, Ochiana SO, Dunphy MP, Gerecitano JF, Corben AD, Peter Rl, et al Heat shock protein 90 inhibitors in the treatment of cancer: current status and future directions. Expert Opin Investig Drugs. 2014;23:611.

11. Basso AD, Solit DB, Munster PN, Rosen N. Ansamycin antibiotics inhibit Akt activation and cyclin D expression in breast cancer cells that overexpress HER2. Oncogene. 2002;21:1159.

12. Solit DB, Zheng FF, Drobnjak M, Münster PN, Higgins B, Verbel D, et al. 17Allylamino-17-demethoxygeldanamycin induces the degradation of androgen receptor and HER2/neu and inhibits the growth of prostate cancer xenografts. Clin Cancer Res. 2002;8:986.

13. Modi S, Saura C, Henderson C, Lin NU, Mahtani R, Goddard J, et al. A multicenter trial evaluating retaspimycin HCL (IPI-504) plus trastuzumab in patients with advanced or metastatic HER2-positive breast cancer. Breast Cancer Res Treat. 2013;139:107.

14. Jhaveri K, Miller K, Rosen L, Schneider B, Chap L, Hannah A, et al. A phase I dose-escalation trial of trastuzumab and alvespimycin hydrochloride (KOS1022; 17 DMAG) in the treatment of advanced solid tumors. Clin Cancer Res. 2012;18:5090

15. Modi S, Stopeck AT, Gordon MS, Mendelson D, Solit DB, Bagatell R, et al. Combination of trastuzumab and tanespimycin (17-AAG, KOS-953) is safe and active in trastuzumab-refractory HER-2 overexpressing breast cancer: a phase I dose-escalation study. J Clin Oncol. 2007;25:5410.

16. Modi S, Stopeck A, Linden H, Solit D, Chandarlapaty S, Rosen N, et al. HSP90 inhibition is effective in breast cancer: a phase II trial of tanespimycin (17AAG) plus trastuzumab in patients with HER2-positive metastatic breast cancer progressing on trastuzumab. Clin Cancer Res. 2011;17:5132. 
17. Friedland JC, Sang J, Modi S, Bradley R, El-Hariry I, Wada Y, Proia DA. Beyond HER2 and hormonal agents: the Heat Shock Protein 90 inhibitor ganetespib as a potential new breast cancer therapy. Cancer Res. 2011;71(24 Suppl): Abstract nr P3-17-05.

18. Ying W, Du Z, Sun L, Foley KP, Proia DA, Blackman RK, et al. Ganetespib, a unique triazolone-containing Hsp90inhibitor exhibits potent antitumor activity and a superior safety profile for cancer therapy. Mol Cancer Ther. 2012;11:475.

19. Jhaveri K, Chandarlapaty S, Lake D, Gilewski T, Robson M, Goldfarb S, et al. A phase II open-label study of ganetespib, a novel heat shock protein 90 inhibitor for patients with metastatic breast cancer. Clin Breast Cancer. 2014;14:154.

20. Nguyen DM, Lorang D, Chen GA, Stewart 4th JH, Tabibi E, Schrump DS. Enhancement of paclitaxel-mediated cytotoxicity in lung cancer cells by 17allylamino geldanamycin: in vitro and in vivo analysis. Ann Thorac Surg. 2001;72:371

21. Solit DB, Basso AD, Olshen AB, Scher HI, Rosen N. Inhibition of heat shock protein 90 function down-regulates Akt kinase and sensitizes tumors to Taxol. Cancer Res. 2003:63:2139.

22. Münster PN, Basso A, Solit D, Norton L, Rosen N. Modulation of HSP90 function by ansamycins sensitizes breast cancer cells to chemotherapyinduced apoptosis in an RB- and schedule-dependent manner. Clin Cancer Res. 2001;7:2228.

23. Eisenhauer EA, Therasse P, Bogaerts J, Schwartz LH, Sargent D, Ford R, et al. New response evaluation criteria in solid tumours: revised RECIST guideline (version 1.1). Eur J Cancer. 2009:45:228.

24. Maier-Lenz H, Hauns B, Haering B, Koetting J, Mross K, Unger C, et al. Phase I study of paclitaxel administered as a 1-hour infusion: toxicity and pharmacokinetics. Semin Oncol. 1997;24 Suppl 19:S19-16-9.

25. Mross K, Holländer N, Hauns B, Schumacher M, Maier-Lenz H. The pharmacokinetics of a 1-h paclitaxel infusion. Cancer Chemother Pharmacol. 2000;45:463-70.

26. Jhaveri K, Modi S. Ganetespib: research and clinical development. Onco Targets Ther. 2015;8:1849.

27. Ramalingam S, Goss G, Rosell R, Schmid-Bindert G, Zaric B, Andric Z, et al. A randomized phase II study of ganetespib, a heat shock protein 90 inhibitor, in combination with docetaxel in second-line therapy of advanced nonsmall cell lung cancer (GALAXY-1). Ann Oncol. 2015;26:1741.

28. Schroder C, Pederson JV, Chua S, Swanton C, Akimov M, Ide S, et al. Use of biomarkers and imaging to evaluate the treatment effect of AUY922, an HSP90 inhibitor, in patients with HER2+ or ER+ metastatic breast cancer. J Clin Oncol. 2011;29 Suppl:Abstract e11024.

29. Jensen MR, Schoepfer J, Radimerski T, Massey A, Guy CT, Brueggen J, et al. NVP-AUY922: a small molecule HSP90 inhibitor with potent antitumor activity in preclinical breast cancer models. Breast Cancer Res. 2008;10:R33.

30. Shapiro Gl, Kwak E, Dezube BJ, Yule M, Ayrton J, Lyons J, Mahadevan D. First-in-human phase I dose escalation study of a second-generation nonansamycin HSP90 inhibitor, AT13387, in patients with advanced solid tumors. Clin Cancer Res. 2015;21:87.

31. Cavenagh JD, Yong K, Byrne J, et al. The safety, pharmacokinetics and pharmacodynamics of KW-2478, a novel HSP90 antagonist, in patients with B-cell malignancies: a first-in-man, phase I, multicentre, open-label, dose escalation study. Blood. 2008:112 Suppl 11:2777.

32. Modi S, Ismail-Khan R, Munster P, Lucas M, Galluppi GR, Tangri S, et al. Phase 1 dose-escalation study of the heat shock protein 90 inhibitor BIIB021 with trastuzumab in HER2+ metastatic breast cancer. Cancer Res. 2010;70 Suppl 2:Abstract P3-14-02.

33. Chiosis G, Timaul MN, Lucas B, Munster PN, Zheng FF, Sepp-Lorenzino L, et al. A small molecule designed to bind to the adenine nucleotide pocket of HSP90 causes Her2 degradation and the growth arrest and differentiation of breast cancer cells. Chem Biol. 2001:8:289.

34. Samlowski WE, Papadopoulos K, Olszanski AJ, Zavitz K, Cimbora DM, Shawbell S, et al. Phase 1 study of HSP90 inhibitor MPC-3100 in subjects with refractory or recurrent cancer. Molecular targets and cancer therapeutics. Mol Cancer Ther. 2011;10 Suppl:Abstract nr A96.

35. Bao R, Lai CJ, Qu H, Wang D, Yin L, Zifcak B, et al. CUDC-305, a novel synthetic HSP90 inhibitor with unique pharmacologic properties for cancer therapy. Clin Cancer Res. 2009;15:4046.

36. Taldone T, Patel PD, Patel M, Patel HJ, Evans CE, Rodina A, et al. Experimental and structural testing module to analyze paralogue-specificity and affinity in the HSP90 inhibitors series. J Med Chem. 2013;56:6803.
37. Isambert N, Hollebecque A, Berge $Y$, Ingen HV, Brienza S, Destaillats A, et al. A phase I study of Debio 0932, an oral HSP90 inhibitor, in patients with solid tumors. J Clin Oncol. 2012;30:Abstract 3026.

38. Fadden P, Huang KH, Veal JM, Steed PM, Barabasz AF, Foley, et al. Application of chemoproteomics to drug discovery: identification of a clinical candidate targeting HSP90. Chem Biol. 2010;17:686.

39. Rajan A, Kelly RJ, Trepel JB, Kim YS, Alarcon SV, Kummar S, et al. A phase I study of PF-04929113 (SNX-5422), an orally bioavailable heat shock protein 90 inhibitor, in patients with refractory solid tumor malignancies and lymphomas. Clin Cancer Res. 2011;17:6831.

40. Menezes DL, Taverna P, Jensen MR, Abrams T, Stuart D, Yu GK, et al. The novel oral HSP90 inhibitor NVP-HSP990 exhibits potent and broad-spectrum antitumor activities in vitro and in vivo. Mol Cancer Ther. 2012;11:730.

41. Spreafico A, Delord JP, De Mattos-Arruda L, Berge Y, Rodon J, Cottura E, et al. Phase I dose-escalation, open-label study of HSP990 administered orally in adult patients with advanced solid malignancies. Br J Cancer. 2015; 112(4):650-9.

42. Bussenius J, Blazey CM, Aay N, Anand NK, Arcalas A, Baik T, et al. Discovery of XL888: a novel tropane-derived small molecule inhibitor of HSP90. Bioorg Med Chem Lett. 2012:22:5396.

43. Gerecitano JF, Modi S, Rampa R, Drilon AE, Fury MG, Gounder MM, et al. Phase I trial of the HSP-90 inhibitor PU-H71. J Clin Oncol. 2015:33 Suppl: Abstract 2537

44. Jhaveri K, Chandarlapaty S, lyengar N, Morris PG, Corben AD, Patil S, et al. Biomarkers that predict sensitivity to heat shock protein 90 inhibitors. Clin Breast Cancer. 2016:16:276

45. Dunphy M, Chiosis G, Beattie B, Gerecitano JF, Bromberg J, Janjigian Y, et al. Progress in first-in-human trial of HSP90-targeted PET imaging in cancer patients. J Nucl Med. 2013;54 Suppl 2:Abstract 279.

46. Gerecitano JF, Modi S, Gajria D, Taldone T, Alpaugh M, DaGama EG, et al. Using 124I-PU-H71 PET imaging to predict intratumoral concentration in patients on a phase I trial of PU-H71. J Clin Oncol. 2013;31 Suppl:Abstract 11076

\section{Submit your next manuscript to BioMed Central and we will help you at every step:}

- We accept pre-submission inquiries

- Our selector tool helps you to find the most relevant journal

- We provide round the clock customer support

- Convenient online submission

- Thorough peer review

- Inclusion in PubMed and all major indexing services

- Maximum visibility for your research

Submit your manuscript at www.biomedcentral.com/submit
Biomed Central 